\title{
O MUNICÍPIO LIBERAL E A DECISÃO POLÍTICA ${ }^{1}$
}

\author{
Justino Magalhães ${ }^{2}$
}

\section{RESUMO}

Desde o final da Idade Média que os concelhos possuíam uma escrita organizada e se foram constituindo como poder público. Legitimados pela eleição dos oficiais camarários, os concelhos eram responsáveis pelo cumprimento dos Usos e Costumes e de outras Posturas municipais. No trânsito do Antigo Regime, emergiam como representantes do público - estatuto que foi retomado e reforçado pelas autoridades revolucionárias e reformadoras do Regime Liberal. A instrução pública tornou-se prerrogativa do Liberalismo. Em Portugal, desde antes da Revolução de 1820 que aumentou a procura da alfabetização. A partir dos anos 40 do século XIX, por iniciativa própria ou pressionados pelo governo central, os municípios portugueses passaram a decidir de forma sistemática em matéria de instrução pública. No processo de autonomia, integração, desenvolvimento e identidade do local, o município constituiu-se como município-pedagógico. Uma historiografia do municipalismo no quadro da modernização educativa, política e social, por paralelo com as histórias nacionais e transversal aos ciclos histórico-pedagógicos, seja na Europa, seja no Novo Mundo - particularmente o Brasil, permitirá a reconstituição e a revisitação das memórias, bem assim como a preservação e informação dos diferentes patrimónios educativos, enfim, da cidadania educativa como móbil da consciência histórica.

Palavras-chave: Município liberal; autarcia escolar; município-pedagógico; cidadania educativa.

\section{THE LIBERAL MUNICIPALITY AND POLICY DECISION}

\begin{abstract}
Since late Middle Ages in Portugal municipalities councils had an organized written and were constituted as a public authority. Legitimated by the election of council's officers, these municipalities' institutions were responsible for the fulfillment of Habits and Customs and other municipal Postures. During the Ancien Régime these institutions emerged as representatives of the people - that status was re-assumed and strengthened by revolutionary and reformist authorities of Liberal Regime. Public education has become as a Liberalism prerogative. In Portugal, since before 1820 Revolution the demand for literacy was increased. From the 40 's of the $19^{\text {th }}$ century, by itself or pushed by the central government, the Portuguese municipalities becomes, systematically, to rule on the field of public education. Developing its identity, autonomy and integration processes, the local municipality was established as a "pedagogical municipality". A historiography of these municipal institutions within the educational, social and polity modernization, besides national and crossing the historical pedagogical cycles, either in Europe or in the New World - specially in Brazil, allow memories reconstitution and discussion, as well the preservation and registration of different educational heritage, taking this educational citizenship as a motor of historical consciousness.
\end{abstract}

Keywords: Liberal municipality; School autarky; Pedagogical municipality; Educational Citizenship. 


\section{O município como instância pública}

Em Portugal, como no Brasil colónia, na transição do Antigo Regime, o município cumpriu um papel de representação, como instância de soberania local e de relação entre o poder local e o poder central. Nas reformas pombalinas para a instrução pública, os concelhos, quando sede de cadeiras de Estudos Menores e de Primeiras Letras, surgem devidamente referidos como tal. Na definição do Plano das Escolas Menores (1772), a Real Mesa Censória tomou a vila urbanizada ou capital de concelho como centro. Com a implementação do Subsídio Literário (1772), as populações recorreram às Câmaras Municipais como força de protesto e de reivindicação, ou como mediação junto do poder central. Os concelhos possuíam uma escrita organizada e tinham vindo a constituir-se como poder público, legitimados pela eleição dos oficiais camarários e responsáveis pelo cumprimento dos Usos e Costumes e de outras Posturas municipais.

No trânsito do Antigo Regime emergiam como representantes do público junto do poder central e junto de outras instâncias do local e do regional. Eram a principal instância de representação e administração do público, estatuto que foi retomado e reforçado pelas autoridades revolucionárias e reformadoras do Regime Liberal. Com a laicização e a emergência do civil, o formalismo religioso recuou, tendendo a ser substituído por hábitos de vida urbana, por regras e protocolos de denominação, formas de trato e comunicação, associados ao município. Este reformismo convergia para o núcleo urbano e o município tornava-se representativo das várias instâncias, organismos e poderes no território concelhio.

Um dos aspectos mais característicos da transformação que conduziu ao declínio e à revolução política que assinala o fim do Antigo Regime é a vulgarização da comunicação escrita, como meio de mobilização e criação de opinião. Com a implantação do Regime Liberal, as questões da instrução pública assumiram uma centralidade que as tornou prerrogativa do regime. Foi entendido que, para um exercício esclarecido da cidadania, era necessário, no mínimo, saber ler, escrever e contar. Assim, assiste-se, desde antes da Revolução de 1820, ao aumento da procura da alfabetização por parte de determinados sectores populacionais, económica e socialmente orientados.

A Revolução Liberal ficou associada a uma participação no exercício do poder e ao fomento de novas formas de representação com base na cultura escrita. Perspectivando estas ideias a partir da história portuguesa, constata-se o crescimento e uma aceleração da comunicação escrita, manifesta em abaixo-assinados e representações enviadas pelas autoridades locais ao poder central. Um dos assuntos mais estudados pela historiografia da educação respeita ao crescimento de representações públicas e de exposições escritas. Eram frequentes os pedidos de criação e abertura de escolas, muito particularmente de Escolas de Primeiras Letras. No caso português, é possível observar um recrudescimento destas solicitações, associado à implementação do já referido imposto do Subsídio Literário.

As autoridades municipais procuraram organizar e disciplinar tais manifestações, que, por vezes, tinham origem em conjuntos de moradores. As representações eram dirigidas, em regra, ao Monarca, mas também as houve dirigidas e outros órgãos de soberania. A título de exemplo, refira-se o seguinte caso. Conhecedora, admita-se, do importante estatuto ocupado pela Junta da Directoria dos Estudos no quadro de uma modernização governativa centrada na escrita, a Câmara de Abrantes encabeçou uma representação escrita, assinada por dezenas de cidadãos, na qual solicitava à Junta da 
Directoria dos Estudos que intercedesse junto do Monarca pela manutenção do Provedor de Abrantes, recordando, entre outros aspectos, "que dos Provedores de Comarca depende a eficácia dos cuidados com a educação e Ensino da Mocidade". Em consequência, os apresentantes argumentavam que o referido Provedor tinha revelado prontidão na resposta aos inquéritos e no exame dos opositores. Datado de 26 de janeiro de 1821, o documento está assinado pela Câmara, Clero, Nobreza e Povo da vila de Abrantes ${ }^{3}$.

\section{Instrução e cidadania}

A Constituição de 1822 consagrou o princípio da livre abertura de escolas. Sob a vigência da Carta Constitucional, a Regência da Ilha Terceira, pelo Decreto de 29 de Março de 1832, estabeleceu a liberdade de ensino público sob a livre protecção das Câmaras e das Juntas de Paróquia. Correlativamente, tinha sido criada uma Comissão para levantamento das necessidades e apresentação de um Plano, na sequência do qual foi publicado o Decreto de 24 de Abril de 1832. Este Decreto consignava a criação de cinco novas Escolas de Primeiras Letras, nas quais seria aplicado o Método de Ensino Mútuo e Aulas de Instrução Secundária. Destas últimas, haveria, na cidade de Angra, uma Aula de Latinidade e História Portuguesa, uma Aula de Retórica, Filosofia e História Universal Antiga e Moderna, uma Aula para o Estudo dos Elementos das Matemáticas e dos Princípios da Física Geral. Na Vila da Praia, seria estabelecida uma Aula de Latinidade e História Portuguesa. Era criada também uma Escola de Meninas, ensinando a ler, escrever e contar, a costura e outros trabalhos semelhantes. As Escolas seriam instaladas em edifícios do Estado e ficavam integradas em núcleos regionais.

O Decreto n. ${ }^{\circ} 24$ de 16 de Maio de 1832, relativo à Reforma da Administração Pública e Reforma Judiciária, estipulava que ler, escrever e contar era condição necessária para a participação na generalidade dos cargos públicos, assim Juízes de Paz, Juízes Ordinários e Juízes Pedâneos (Art. ${ }^{\circ}$ 31), como também Jurados (Art. ${ }^{\circ}$ 32). Pelo Decreto de 6 de Junho de 1832, foram criadas novas Aulas para as Ilhas de S. Miguel e de Santa Maria. Nos termos desta legislação, a função de jurado passava a ser necessária para o regular funcionamento dos tribunais de Comarca e cabia à municipalidade, cabeça de julgado, proceder à constituição da Pauta de Jurados, que serviriam em cada quarto de ano. A função de Jurado era de cumprimento obrigatório. Integrado num quadro legislativo de atribuição aos Cidadãos locais, da participação e da obtenção do bem comum, as autoridades municipais sentiam-se na obrigação de fomentar a instrução. Em face das prerrogativas da lei e da inexistência de cidadãos alfabetizados que assegurassem a rotatividade dos jurados, mesmo com o alargamento do período de exercício para seis meses, alguns julgados tiveram de encerrar.

Para ser eleitor era, em regra, recomendado que o cidadão soubesse ler, escrever e contar; para a função de jurado, tais capacidades tornavam-se imprescindíveis e condição necessária. A função de jurado envolvia uma jurisprudência assente na permanente articulação entre a legislação aplicável e a realidade local. Para tal, o jurado carecia não apenas do conhecimento e interpretação dos instrumentos legais, quanto da percepção crítica da realidade envolvente, que lhe permitisse conhecer, conceptualizar e avaliar as situações de conflito, nomeadamente em matéria criminal. Era, para todos os efeitos, uma função de compromisso, com repercussões na integração social e política. 


\section{Os municípios no fomento da instrução pública}

Há congruência entre o município como instância de representação e soberania e o município com obrigações de justiça e mobilização dos cidadãos para a administração. No contexto da Revolução Liberal, a alfabetização era condição de participação, mas era a escola que assegurava a formação de pares e a congregação de vontades. A acção do município era instituinte, complementando o complexo concelhio de representação, administração, regulamentação, jurisdição.

Com os Liberais no governo do País, foi criada, pelo Decreto de 2 de Março de 1833, uma Comissão para "propor um plano geral d'Estudos, Educação e Ensino Público, - a criação dos Estabelecimentos Literários, que julgar necessários, - e a competente reforma" dos existentes, incluindo a Universidade de Coimbra, Academias, Colégios, Escolas. Neste Plano, os municípios eram, uma vez mais, os principais centros de referência.

Ainda que de vigência efémera, a Reforma assinada em 1835 por Rodrigo da Fonseca Magalhães entregava o estabelecimento, a manutenção e a conservação das escolas às Municipalidades e Juntas de Paróquia respectivas. A orientação de regular e conferir aos municípios um estatuto de centro de desenvolvimento, com capacidade de decisão, foi prosseguida pela legislação setembrista, assinada por Passos Manuel. No âmbito da promulgação do Código Administrativo de 1836 e da sequente Reforma Administrativa, foi reduzido o total de municípios e correlativamente fortalecida a soberania dos concelhos. Foram extintos 466 dos 817 concelhos então existentes. A legislação setembrista consignou que as Câmaras pagariam aos professores das Escolas do Ensino Primário o complemento de ordenado de vinte mil réis. Estabeleceu também que, em cada Concelho, fosse formada uma Comissão Inspectora da Instrução Primária. Esta Comissão, presidida pelo Administrador do Concelho, contaria com um Vogal, nomeado pela Câmara, e com um Comissário da Universidade, que serviria de Secretário; este último seria um professor, nomeado pela Direcção Geral, que residisse no Concelho (Decreto de 15 de Novembro de 1836, Art. $^{\circ} 37^{\circ}$ ).

Desde os anos 40 do século XIX que, por iniciativa própria ou pressionados pelos Governos Civis, os municípios passaram a decidir de forma sistemática em matéria de instrução: criação e transferência de escolas, fomento e reconhecimento de escolas paroquiais, elaboração da folha de pagamento aos professores. Em consequência, observou-se uma expansão da rede escolar.

Saber como e a partir de que data cada município passou efectivamente a cumprir as disposições do poder central (que chegavam através dos administradores concelhios e dos governadores civis) varia de concelho para concelho. A título de exemplo, assinale-se que, em Dezembro de 1841, a Câmara Municipal de Lisboa deliberou que não pagaria aos Professores de Instrução Primária, sem que o Administrador legalizasse tais vencimentos ${ }^{4}$. No encerramento das contas de 1842, em face da dívida acumulada, a mesma Câmara Municipal deliberou que pagaria os meses mais antigos em dívida. Vejamos um outro caso. Na Sessão de 23 de Maio de 1843, a Câmara Municipal de Sintra deliberou sobre o ofício do Mestre de primeiras letras da vila, que solicitava o pagamento da "verba de $2.137 \$ 000$ réis [sic]", devida pelo exercício de funções entre 21 de Fevereiro e 31 de Março desse ano. O mesmo Mestre solicitava também a "verba de 2.400\$000 [sic]" referente à renda da Casa da Aula ${ }^{5}$.

Em conformidade com o Código Administrativo de 1842, o total de municípios portugueses era em número de 411. Parte desses municípios tinha já então organizado a 
folha de pagamento e integrado no orçamento camarário as verbas destinadas aos professores. A Reforma Costa Cabral (1844) tomou o município como território e centro ordenador da oferta escolar. De alçada paroquial, as Escolas de Primeiras letras faziam parte da rede municipal, como dela faziam parte as Cadeiras de Estudos Menores e as Escolas Municipais. A Reforma Costa Cabral para a Instrução Pública atribuiu aos municípios a manutenção das Cadeiras de Primeiras Letras (pagamento a professores, mestres e mestras, vigilância sobre as condições de acesso, segurança e habitabilidade das instalações escolares). Cada Câmara Municipal tinha a sua política para a instrução pública. A Câmara Municipal de Lisboa, que havia preservado a autonomia face à estatalização pombalina, na sequência das leis regeneradoras, criou, por deliberação de 4 de Abril de 1852, o Pelouro das Escolas ${ }^{6}$.

\section{Ensino e soberania municipal}

No livro publicado em 1856 sobre a Reforma dos Municípios, em que retomava os princípios fundamentais que tinham sido avançados por Almeida Garrett, Henriques Nogueira colocou o município no centro da regeneração e do progresso, como instância de formação e de cidadania: "O município é a melhor escola de educação pública. Nele os cidadãos aprendem a usar dos seus direitos e a cumprir os seus deveres políticos, tratando de objectos que imediatamente os interessam e que por isso facilmente compreendem"7. Convidado para aceitar concorrer a deputado pelo Círculo Eleitoral de Sintra, em 1858, Alexandre Herculano declinou, aproveitando o ensejo para escrever uma longa carta, na qual defendia a conveniência de os representantes serem escolhidos e eleitos entre os membros da localidade, como condição para "a administração do país pelo país (...) [para o que] é necessário começar pelo princípio; é necessário que a vida pública renasça"8. Herculano associava a instrução à modernização da administração, referindo-se a uma metapolítica que restaurasse a vida municipal e a eleição singular, focalizada em homens de bem, cujos interesses se cruzassem com os dos eleitores, independentemente do partido político a que pudessem pertencer. Opôs o país da realidade - o país dos casais, das aldeias, das vilas, das cidades, das províncias - ao país nominal, inventado nas secretarias, nos quartéis, nos clubes, nos jornais, e constituído pelas diversas camadas do funcionalismo.

A legislação reguladora da década de 60 do século XIX, tendo a estatística como elemento de comparação e racionalidade e o município como célula básica, tornou possível a autonomização dos municípios. A partir de 1866, na sequência da implementação do legado Conde Ferreira, foi criada uma planta para o edifício escolar. Cumpridos os condicionalismos legais, os municípios passaram a intervir na planificação da rede escolar. A título de exemplo, refira-se uma vez mais o caso da Câmara Municipal de Sintra, que, por deliberação de 17 de Junho de 1863, propôs a suspensão da Aula de Latim e a criação de duas Cadeiras de Ensino Primário. E em ofício ao Administrador do Concelho, remetido em 5 de Agosto de 1863, a mesma Câmara comprometeu-se a concorrer com o subsídio da lei e a oferecer casa para aquelas duas novas escolas.

As decisões sobre a criação de escolas ou mudanças das sedes de escola foram habituais na generalidade dos municípios. No entanto, a soberania dos municípios incluiu outro tipo de decisões. Refira-se o seguinte caso ocorrido com a Câmara Municipal de Ponta Delgada, que vem reportado na Acta de Câmara de 10 de Janeiro de 1867: 
Recebeu-se um ofício do Sr. Administrador do Concelho, com data de 8 do corrente, participando as inconveniências que se tem dado na escola do sexo masculino da Fajam de Cima, que tornam impossível a continuação do professor Joaquim Pedro de Sousa Calado; o que sendo tomado em consideração, e tendo-se em vista as informações que se apresentaram sobre a irregularidade do procedimento do dito Professor; resolveu a Camara demiti-lo, como de facto demite, anunciando-se vaga e a concurso a referida escola. ${ }^{9}$

Tomando por referência o Município de Ponta Delgada, nas várias componentes que compõem o governo municipal relativo ao ensino, observa-se uma acção concertada e de sentido autonómico - uma autarquia. Nos assuntos de Câmara, são tratados de forma articulada a cobrança de impostos, a sanidade pública, a segurança. Igualmente se observa que o fomento da autonomia era articulado com os poderes central, municipal, paroquial.

Pode admitir-se que, de uma forma geral, o municipalismo traduz a dialéctica em que, não raro, estiveram em curso uma racionalidade escalar e uma concertação com o exterior, visando o exercício autonómico e sustentado da decisão e da projecção quanto ao futuro, mesmo que com prejuízo da estreita concentração autárcita. O município era uma instância intermédia e de mediação, pelo que, em boa parte, a efectiva consolidação dos seus desígnios era incompatível com uma política de fechamento.

\section{Autarcia escolar e municipalismo}

Nos diferentes contextos históricos sequentes à Revolução Francesa e Ocidental, os municípios foram sucessivamente tomados em consideração.

Em França, uma ordenação de 29 de Fevereiro de 1816 tinha criado um comité cantonal em cada comuna e admitia a existência de escolas fundadas ou sustentadas pelas comunas e de escolas mantidas por associações de benfeitores ou por particulares. Publicada em 1833, a lei Guizot prescrevia a obrigação de cada comuna com mais de 500 habitantes abrir uma escola primária e de existir em cada vila com mais de 6000 habitantes uma escola primária superior. Na sequência desta lei, deveria ser criado um comité comunal, presidido pelo prefeito ou sub-prefeito, que incluía o juiz de paz, o procurador do rei, um ministro de cada um dos cultos reconhecidos, um membro do ensino secundário, público ou privado, um membro do ensino primário, três membros do conselho de circunscrição e os conselheiros gerais residentes na circunscrição ${ }^{10}$. Por uma ordenação de 26 de Fevereiro de 1835, foi instituído um inspector em cada departamento, que, deste modo, era a primeira entidade independente das autoridades locais. A lei de 10 de Abril de 1867 passou a contemplar também a escola local - "l'école de hameau", e não apenas a escola comunal; ambas formavam um sistema escolar comunal. A lei de 1 de Junho de 1878 sobre construções escolares prescrevia que as comunas assegurassem a instalação, aquisição, apropriação e construção das escolas locais, bem como do material escolar. Desde 1876 que o modelo de escolas a construir era enviado aos Prefeitos. Com a III República, a oferta municipalista de instrução foi estruturante e condição do cumprimento da obrigatoriedade escolar.

Em Espanha, o processo de modernização ficou assinalado por uma componente autárcita de base municipal e por uma tensão entre federalismo e provincialismo. Os poderes e instâncias locais tiveram um papel determinante na salvaguarda das línguas e das etnografias regionais, contrapondo-as a uniformização estatal. 
Na Bélgica, o sistema escolar constituiu-se com expressões e estruturas distintas de cantão para cantão, tomando a matriz municipal como célula-base.

Tornado independente no contexto da Revolução Ocidental, o Estado brasileiro assenta na Constituição de 1824, cujo Artigo 167 consagra que "Em todas as cidades e vilas ora existentes, e nas mais que para o futuro se criarem, haverá câmaras, às quais compete o governo económico e municipal das cidades e vilas"11. A Lei Orgânica do poder municipal, publicada em 1 de Outubro de 1828, estipulava no Artigo 70 que as Câmaras:

Terão inspeção sobre as escolas de primeiras letras, educação e destino dos órfãos pobres, em cujo número entrarão os expostos, e quando estes estabelecimentos, e os de caridade, de que trata o artigo 69, se achem por lei, ou de fato, encarregados em alguma cidade ou vila, a outras autoridades individuais ou coletivas, as câmaras auxiliarão sempre quanto estiver da sua parte para a prosperidade e aumento dos sobreditos estabelecimentos. ${ }^{12}$

Na sequência da publicação do Ato Adicional de 1834, o poder camarário, exercido com margem de autonomia, era regulado pelas Assembleias Legislativas Provinciais, designadamente no que respeitava à instrução pública.

Em Portugal, nas últimas décadas do século XIX, actuando no quadro de municipalização regulamentado pelas leis de 1878 e 1885, assinadas por Rodrigues Sampaio, as Câmaras Municipais, articulando educação, protecção e instrução, assumiramse como territórios educativos, executando uma política de fomento da instrução pública que se revestiu de uma polaridade e atracção urbanas.

Com efeito, o conjunto de oficiais e de funções ligadas à administração pública (contabilidade, comércio, construção civil, indústria, transporte, comunicação, electrificação, correios, escritórios, etc.) constituiu uma diversificação da estrutura social e da malha das relações e dos modos de produção, criando um lugar e uma oportunidade explícita e gratificante para aqueles que tinham acesso e oportunidade de instrução. $\mathrm{O}$ município passou a dispor de uma administração e de órgãos específicos para o fomento da instrução e da educação públicas. As autoridades locais dispuseram de oportunidade para formarem e politizarem os seus cidadãos. A integração municipal encontrou na instrução pública uma construção de identidade. Na sequência das leis municipalistas, o total de escolas cresceu no todo nacional, ainda que o crescimento tenha sido mais notório nos distritos do interior do País.

\section{O município pedagógico - horizontes e limites}

Ao estabelecer uma diacronia de longa duração na Modernização Educativa ocidental $^{13}$, assinalei um ciclo de nacionalização, que deu coerência ao liberalismo e um ciclo de governamentação, em que a realidade escolar gerou uma burocracia escrita e orgânica. São ciclos que, comportando a diferenciação, determinaram de forma consequente a implementação de uma política escolar comum, estruturada no quadro da estatalização.

No âmbito das Reformas Judiciais e Administrativas, saídas do quadro constitucional, as pequenas escolas passaram a ser confiadas às instâncias governativas das localidades, como garantia do seu efectivo funcionamento. Esta prática teve repercussão no recenseamento da infância, na modernização da administração pública, na aplicação da 
justiça. Em regra, a geografia escolar de Primeiras Letras estava indexada à das paróquias e comunas. A promoção escolar foi aberta à iniciativa privada, em regime de complementaridade. A generalidade das escolas primárias inglesas, belgas, americanas, estava confiada às autoridades religiosas ou às comunas e municipalidades.

No quadro da Modernidade, associado ao aumento demográfico e à humanização da paisagem, o urbano sobrepôs-se ao rural, conglomerando as populações, encurtando as distâncias, entretecendo novas sociabilidades. Nesse quadro de mudança, a cultura escrita tornou-se meio de comunicação por excelência. Através da memória municipal, urbana e rural, a educação escolar passou a fazer parte do núcleo transformativo. Neste contexto, a informação, a participação e as práticas de sociabilidade, bem assim como o exercício da cidadania, encontraram na cultura escrita o principal meio, mas também os arquivos e os museus se converteram em instituições fundamentais da identidade e da integração municipalista.

$\mathrm{Na}$ autonomização, na integração local, no desenvolvimento e no progresso, o município tendeu a constituir-se como município-pedagógico. Dando consequência ao município administrativo e ao município social, as autarquias projectaram, idealizaram e puseram em marcha programas de educação e instrução, num quadro de complemento da acção estatal, mas frequentemente também levando a sua autonomia até à criação de uma oferta educativa própria, que incluía a rede escolar, os professores, os cursos profissionais. Beneficiando de território e economia próprios, o município fomentou a manutenção e a ampliação de um horizonte evolutivo e de uma autarcia, dispondo de soberania e de poder de decisão. A história do municipalismo revela uma participação cívica, uma memória e uma mobilização colectivas que tornaram o poder concelhio uma instância fundamental para a história da educação.

Procurando sintetizar, pode concluir-se que, beneficiando de território e economia próprios, o município fomentou a manutenção e a ampliação de um horizonte evolutivo e de uma autarcia, dispondo de soberania, poder de decisão e representando um factor de identidade e garantia de futuro para os autóctones e para as populações em trânsito. A historicidade do município educativo, muito particularmente na versão projectiva de município pedagógico, desafia a uma teorização do local como instância de decisão, ideação e realização. Desafia, de igual modo, à sistematização de uma historiografia do municipalismo no quadro da modernização educativa, política e social, por paralelo com as histórias nacionais e como instância de transversalização dos ciclos histórico-pedagógicos, seja na Europa, seja no Novo Mundo, particularmente o Brasil. Não pode deixar de implicar também a reconstituição histórica a partir da revisitação das memórias, da salvaguarda, preservação e informação dos diferentes patrimónios educativos, da cidadania educativa como móbil da consciência histórica.

Com as transformações políticas que assinalam a transição do Antigo Regime, os municípios, denominados em função da topologia e do estatuto, assumiram a função de representação, formalizando e dando sequência às reivindicações das populações locais junto do poder central. Com a difusão dos ideários liberais, os municípios favoreceram e tornaram realidade o exercício da cidadania, e assumiram obrigações de fomentar a alfabetização associada à modernização da administração. Esta função/ obrigação evoluiu para uma polarização de soberanias e poderes de decisão, consolidando estratégias e ideários autonómicos. 


\section{Referências}

Alexandre Herculano. Carta aos Eleitores do Círculo Eleitoral de Cintra. Lisboa: Typographia do Jornal do Commercio, 1858.

ANTT, Fundo do Ministério do Reino, Secretarias de Estado, Cx. 1125.

Françoise Mayeur. De la Révolution à l'Ecole républicaine. In Louis-Henri Parias (dir.). Histoire de l'Enseignement et de l'Éducation en France, Tome III. Paris: Nouvelle Librairie de France, 1981, p. 320.

J. Félix Henriques Nogueira. O Município no Século XIX. Lisboa: Typographia do Progresso, 1856, p. 205.

Justino Magalhães. Da Cadeira ao Banco. Escola e Modernização (Séculos XVIII-XX). Lisboa: Educa, 2010.

Livro de Acórdãos da Câmara Municipal de Ponta Delgada, de Junho de 1866 a Setembro de 1868, p. 94.

Livro de Actas da Câmara [de Sintra], nº 8, p. 39.

Sinopse dos principais Actos Administrativos da Câmara Municipal de Lisboa, 1839/ 1845. Lisboa: Imprensa Nacional, 1846, p. 42.

Sinopse dos principais Actos Administrativos da Câmara Municipal de Lisboa, 1853. Lisboa: Imprensa Nacional, 1854, pp. 27-31.

Wenceslau Gonçalves Neto. O Município e a Educação em Minas Gerais. A implementação da Instrução Pública no início do Período Republicano. In Wenceslau Gonçalves Neto e Carlos Henrique de Carvalho (Org.). O Município e a Educação no Brasil. Minas Gerais na Primeira República. Campinas SP: Editora Alínea, 2012, p. 27.

Notas:

\footnotetext{
${ }^{1}$ Este texto integra-se no Atlas Repertório dos Municípios da Educação e da Cultura em Portugal (18201986), Projecto PTDC/CPE-CED/116938/2010, financiado pela FCT - Fundação para a Ciência e Tecnologia.

${ }^{2}$ Professor catedrático do Instituto de Educação da Universidade de Lisboa/ Portugal. Endereço eletrônico: justinomagalhaes@ie.ul.pt

${ }^{3}$ ANTT, Fundo do Ministério do Reino, Secretarias de Estado, Cx. 1125.

4 Sinopse dos principais Actos Administrativos da Câmara Municipal de Lisboa, 1839/ 1845. Lisboa: Imprensa Nacional, 1846, p. 42

${ }^{5}$ Livro de Actas da Câmara [de Sintra], no 8, p. 39

${ }^{6}$ Sinopse dos principais Actos Administrativos da Câmara Municipal de Lisboa, 1853. Lisboa: Imprensa Nacional, 1854, pp. 27-31.

${ }^{7}$ J. Félix Henriques Nogueira. O Município no Século XIX. Lisboa: Typographia do Progresso, 1856, p. 205.

${ }^{8}$ Alexandre Herculano. Carta aos Eleitores do Círculo Eleitoral de Cintra. Lisboa: Typographia do Jornal do Commercio, 1858.
} 
${ }^{9}$ Livro de Acórdãos da Câmara Municipal de Ponta Delgada, de Junho de 1866 a Setembro de 1868, p. 94.

${ }^{10} \mathrm{Cf}$. Françoise Mayeur. De la Révolution à l'Ecole républicaine. In Louis-Henri Parias (dir.). Histoire de l'Enseignement et de l'Éducation en France, Tome III. Paris: Nouvelle Librairie de France, 1981, p. 320.

${ }^{11}$ Apud Wenceslau Gonçalves Neto. O Município e a Educação em Minas Gerais. A implementação da Instrução Pública no início do Período Republicano. In Wenceslau Gonçalves Neto e Carlos Henrique de Carvalho (Org.). O Município e a Educação no Brasil. Minas Gerais na Primeira República. Campinas SP: Editora Alínea, 2012, p. 27.

${ }^{12}$ Idem, p. 27.

13 Justino Magalhães. Da Cadeira ao Banco. Escola e Modernização (Séculos XVIII-XX). Lisboa: Educa, 2010.

Recebido em fevereiro-14

Aprovado em março-14 